\title{
Effects of Manual Continuous Home Cervical Traction in Cervical Spondylosis
}

\author{
Shakoor $\mathrm{MA}^{1^{*}}$, Emran $\mathrm{MA}^{1}$, Zaman $\mathrm{AKA}^{2}$, Moyeenuzzaman $\mathrm{M}^{1}$ \\ ${ }^{I}$ Department of Physical Medicine \& Rehabilitation, Bangabandhu Sheikh Mujib Medical \\ University, Dhaka, Bangladesh; ${ }^{2}$ Physical Medicine \& Rehabilitation, BIRDEM General Hospital, \\ Dhaka, Bangladesh
}

\begin{abstract}
Background: Cervical spondylosis is the results of disc degeneration with associated osteophytosis. Cervical traction is widely used to treat neck disorders. Rehabilitation treatment like cervical traction along with other measures at home may play an important role to reduce symptoms of the patients with cervical spondylosis.
\end{abstract}

Objective: A randomised clinical trial was conducted among 125 patients having cervical spondylosis to find out the effects of manual continuous home cervical traction.

Methods: The patients were selected on the basis specific selection criteria. They were subdivided into two groups. In Group-A (manual continuous home cervical traction group), 61 patients were treated with exercise, cervical collar, neck support, manual continuous home cervical traction, NSAID, warm moist compression and instruction in posture. In Group-B (conventional treatment receiving group), 64 patients were treated with exercise, cervical collar, neck support, warm moist compression, NSAID and instruction in posture.

Results: Among the subjects there were 68 (54.4\%) male and 57 (45.6\%) female. The mean age of the subjects was $45.94 \pm 11.65$ years. There was marked improvement of symptoms of the patients of Group-A in response to treatment for 6 weeks $(p<0.007)$. It indicates that manual home cervical traction was found effective to reduce the sign and symptoms of cervical spondylosis. There was improvement after treatment in Group-B also $(p<0.01)$. It indicates that conventional treatment was also found effective. In comparison, there was no significant difference between two groups $(p<0.36$, $95 \% \mathrm{CI}=-0.56$ to 1.51 ) found after first week. But there was significant improvement in Group-A than Group-B after six weeks of treatment ( $p<0.003,95 \% \mathrm{CI}=-2.40$ to -0.51$)$.

Conclusion: It may be concluded that manual continuous home cervical traction is beneficial for the patients with cervical spondylosis.

Keyword: Cervical Spondylosis, Cervical Traction, Home Cervical traction, NSAID.

\section{Introduction}

Neck pain is very common among the patients attending the hospital and in the private practice. Neck pain is seen frequently as a presenting symptom in clinical practice and sometimes compromise the work capacity. Most of the patients are suffering from cervical degenerative diseases. Osteoarthritis is a common rheumatological disease that affects more than $80 \%$ of the people aged 55 years and older. ${ }^{1}$ Cervical spondylosis is the results of disc degeneration with associated osteophytosis. ${ }^{2}$ Degeneration in the cervical spine may be associated with pain in the neck but usually only when the degenerative changes are severe.

Mild to moderate cases usually remain asymptomatic. Pain of mechanical disorders is

*Correspondence: Dr. MA Shakoor, Department of Physical Medicine \& Rehabilitation, Bangabandhu Sheikh Mujib Medical University, Dhaka,

Bangladesh; E-mail: dmashakoor04@yahoo.com; ORCID: 0000-0001-6801-9179 intermittent and increased due to activity. Pain referred to the arm may indicate entrapment of the nerve fiber at the root. Common causes are a prolapsed disc or degenerative changes, including apophyseal joint or ligamentous hypertrophy and

osteophytes formation but neurological examination often reveals the level of entrapment. ${ }^{3}$ Life time prevalence of cervical pain is $67-71 \%$ and it can cost 29 billion US dollars in USA. ${ }^{4}$ Khan $\mathrm{K}$ et al described that the annual prevalence between $15.0 \%$ and $50.0 \%$ in some studies and middle aged females show much higher frequency of neck pain. ${ }^{5}$ Qayyum $S$ et al also showed that cervical spondylosis is highly prevalent. ${ }^{6}$ Cervical traction with regular physiotherapy modalities like Transcutaneous Electrical Nerve Stimulation (TENS), hot pack and ultrasound accompanied by home exercises for three weeks increased hand grip strength on the affected arm and reduced neck and arm pain substantially in C7 radiculopathy due to herniated disc. ${ }^{7}$ 
It commonly affects people more than 40 years aged persons and is responsible for varying grades of disability. ${ }^{7}$ Alom et al found the Rheumatology clinic at the department of Physical Medicine, Institute of Post-Graduate Medical and Research (IPGMR) and found that cervical spondylosis was the commonest lesion $(23.5 \%)$ amongst the various rheumatic disorders. ${ }^{8}$ The use of exercises, aids and appliances, TENS and other electromagnetic applications, are widely used by many specialists. 9,10 Several types of physical therapy and patient education have beneficial effects on musculoskeletal pain. ${ }^{11-14}$ Cervical traction is widely used to treat neck disorders. In a study it was found that motorized cervical traction is effective in cervical spondylosis. ${ }^{12}$ Rehabilitation treatment like cervical traction along with other measures at home may play an important role to reduce symptoms of the patients with cervical spondylosis. For this purpose, an effort was made to assess the effects of manual continuous home cervical traction on the patients with cervical spondylosis to improve the present situation and to reduce disability and recurrence of symptoms of this type of patients.

\section{Materials and Methods}

A randomized clinical trial was conducted during the period of July 2012 to June 2013 to assess the effects of manual continuous home cervical traction on cervical spondylosis. The patients having cervical spondylosis were selected from the outpatient department of Physical Medicine and rehabilitation of Bangabandhu Sheikh Mujib Medical University (BSMMU). They were selected based on the criteria used in the trial of 1966 with some modification, sponsored by the British Association of Physical Medicine. ${ }^{15}$

Inclusion criteria: (i) Pain in the neck having a root distribution and being associated with limited and painful movement of the neck; (ii) Pain with full root distribution with paresthesia but without clinical evidence of abnormality; (iii) Chronic pain and stiffness of the neck with or without any root distribution; and (iv) Age more than 30 years or less than 60 years.

Exclusion criteria: (i) Patients with rotator cuff tears, tennis elbow and carpal tunnel syndrome; (ii) Patients with abnormal neurological signs indicating cord compression; (iii) Patients having rheumatoid arthritis, tuberculosis, hepatic \& renal disorder or has a bony injury to the cervical spine; and (iv) Patients with acute neck pain.
Before admission into the trial, Institutional Review Board of the BSMMU approval was taken. Informed consent of the patients was taken. History, clinical examination and relevant investigations were done and they were followed weekly for six weeks. About 145 patients were included and were randomly allocated into two groups by the way of lottery. But 20 patients were dropped out.

Group-A (manual continuous home cervical traction group): Here, 61 patients were treated with selective physical modalities that is - exercise, cervical collar, neck support, manual continuous home cervical traction, NSAID, warm moist compression and instruction in posture.

Group-B (conventional treatment receiving group): Here, 64 patients were treated with exercise, shoulder elevation exercise, cervical collar, neck support, warm moist compression, NSAID and instruction in posture.

Cervical traction was given by a manual continuous home cervical traction set in sitting position. The angle of pull was $15^{\circ}$ flexion of the cervical spine. The traction was given continuously for 20 minutes every day at home. The weight of traction in the trial was $15.0 \%$ (approx.) of the subject's body weight. Exercise was given in the form of isometric neck muscle strengthening exercise and shoulder elevation exercise. The exercise was given for 10 repetitions twice daily and posture correction advice was given to all. Posture correction regarding sitting, lying, reading, writing, shaving, chocking bending etc were clearly explained to the patients. A cervical collar was prescribed for all the subjects for posture correction and it was used during activity but not during the time of sleeping. NSAIDs in the form of Naproxen $(250 \mathrm{mg})$ twice daily after meals and omeprazole $(20 \mathrm{mg})$ was given twice daily to prevent drug induced peptic ulcer by NSAIDs to all the patients.

All the patients were assessed initially and weekly for six weeks. Assessment was done by pain score, tenderness index, pain frequency score and visual analogue scale. The results were expressed as percentage, frequencies, mean $\pm \mathrm{SD}$ and the level of significant was expressed by $p$-value unless otherwise stated. Both paired and unpaired Student's ' $t$ ' tests were done as required to find out the level of significance.

\section{Results}

A total of 125 patients were duly participated in the study. Among them, there were 68 (54.4\%) 
male and 57 (45.6 \%) female (fig. 1). The male female ratio was 1: 0.83 . Most of the subjects were married $(95.2 \%)$.

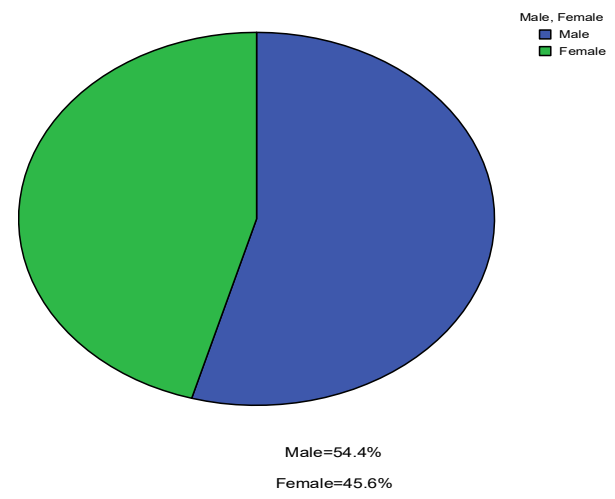

Figure 1: Sex distribution of the patients $(\mathrm{N}=125)$

$N=$ Total number of patients included in the study Among them there were 68(54.4\%) male and 57 (45.6\%) female.

Maximum patients were in the middle class $(60.8 \%)$. The mean age of the subjects was $45.96 \pm$ 11.7 years. The highest number of patients was in the $40-49$ years age group (Figure 2).
Regarding occupation of the patients, maximum patients of cervical spondylosis were housewife $(39.2 \%)$ and the table workers were in the second position (20.8\%). Baseline clinical characteristics of the patients in both the group were identical (table I).

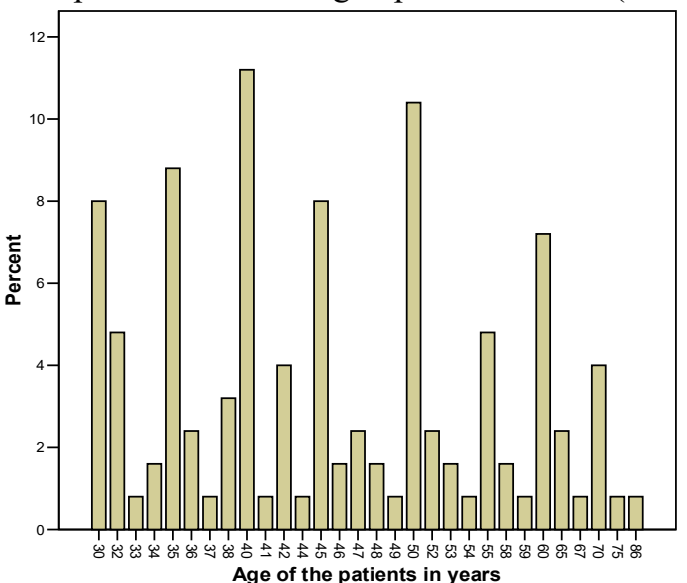

Figure 2: Age distribution of the patients $(\mathrm{N}=125)$

$\mathrm{N}=$ Total number of patients included in the study The mean age of the subjects was $45.94 \pm 11.65$ years.

The highest number of patients was in the $40-49$ years age group.

Table I: Distribution of baseline clinical characteristics of the patients included in the clinical trial.

\begin{tabular}{|c|c|c|c|c|c|c|}
\hline Groups & Age in years & Pulse / m & $\begin{array}{c}\text { Systolic BP } \\
\text { (m m of Hg) }\end{array}$ & $\begin{array}{l}\text { Diastolic BP } \\
\text { (m m of } \mathbf{H g})\end{array}$ & ESR in $1^{\text {st }}$ hours & $\begin{array}{c}\text { 2HPPBS } \\
(\mathrm{mmol} / \mathrm{L})\end{array}$ \\
\hline $\begin{array}{l}\text { Group-A } \\
(n=61)\end{array}$ & $45.9 \pm 11.6$ & $81.18 \pm 7.7$ & $121.2 \pm 13.7$ & $78.5 \pm 8.8$ & $21.8 \pm 15.5$ & $114.73 \pm 27.9$ \\
\hline $\begin{array}{l}\text { Group-B } \\
(n=64)\end{array}$ & $45.92 \pm 11.8$ & $81.67 \pm 8.4$ & $121.2 \pm 13.1$ & $78.2 \pm 8.1$ & $21.58 \pm 18.7$ & $118.28 \pm 35.3$ \\
\hline$p$ - value & 0.98 & 0.73 & 0.96 & 0.84 & 0.93 & 0.53 \\
\hline $95 \%$ CI & -4.11 to 4.17 & -3.34 to 2.36 & - 4.70 to 4.79 & -2.68 to 3.30 & -5.80 to 6.31 & -14.78 to 7.68 \\
\hline
\end{tabular}

Group- $A=$ Manual continuous home cervical traction group

Group $-B=$ Conventional treatment receiving group

Treatment response in Group-A (manual continuous home cervical traction group): There was marked improvement of the condition of the patients in response to treatment for 6 weeks. The numerical data of pre-treatment and after treatment assessment scores of this group were compared statistically (paired student's ' $t$ ' test) and found highly significant ( $p<0.007$. $95 \% \mathrm{CI}=7.09$ to 8.80 , table II). So, manual continuous home cervical traction was found significantly effective to reduce the sign and symptoms of cervical spondylosis.

Table II: Distribution of pre-treatment and post-treatment improvement within groups

\begin{tabular}{lcc}
\hline & Group-A (n=61) & Group-B (n=64) \\
\hline $\begin{array}{l}\text { Pre-treatment } \\
\text { scores }\end{array}$ & $13.79 \pm 2.93$ & $13.31 \pm 2.91$ \\
$\begin{array}{l}\text { Post-treatment } \\
\text { scores } \\
\boldsymbol{p} \text {-value }\end{array}$ & $5.84 \pm 2.87$ & $7.30 \pm 2.44$ \\
$\mathbf{9 5 \%} \mathbf{C I}$ & 7.09 to 8.80 & 0.01 \\
\hline $\begin{array}{l}\text { Group-A }=\text { Manual continuous home cervical traction group } \\
\text { Group- } B=\text { Conventional treatment receiving group }\end{array}$
\end{tabular}

Treatment response in Group-B (conventional treatment receiving group): There was improvement of the patients in response to treatment for 6 weeks. The numerical data of pretreatment and after- treatment assessment scores of this group were compared statistically (paired student's ' $\mathrm{t}$ ' test) and found highly significant ( $p<$ $0.01,95 \% \mathrm{CI}=5.21$ to 6.81 , table III). So, NSAIDs were also found effective to reduce the sign \& symptoms of cervical spondylosis.

Table III: Distribution of pre-treatment and post-treatment comparative improvement between two groups

\begin{tabular}{lcc}
\hline & $\begin{array}{c}\text { pre-treatment } \\
\text { scores }\end{array}$ & $\begin{array}{c}\text { post-treatment } \\
\text { scores }\end{array}$ \\
\hline Group-A $(\mathbf{n}=\mathbf{6 1})$ & $13.79 \pm 2.93$ & $5.84 \pm 2.87$ \\
Group-B $(\mathbf{n}=\mathbf{6 4})$ & $13.31 \pm 2.91$ & $7.30 \pm 2.44$ \\
$\mathbf{p - v a l u e}$ & 0.36 & 0.003 \\
$\mathbf{9 5 \%} \mathbf{C I}$ & -0.56 to 1.51 & -2.40 to -0.51 \\
\hline $\begin{array}{l}\text { Group- } A=\text { Manual continuous home cervical traction group } \\
\text { Group- } B=\text { Conventional treatment receiving group }\end{array}$
\end{tabular}


Overall comparative improvement between two groups: At the time of first visit, there was no significant improvement between two groups $(p<00.36,95 \% \mathrm{CI}=-0.56$ to 1.51$)$ but on the other hand there was significant improvement in Group-A than Group-B after six weeks treatment $(p<00.003,95 \% \mathrm{CI}=-2.40$ to -0.51 , table III). This result indicates that the improvement of the patient with cervical spondylosis was seen better in manual continuous home cervical traction group than that of conventional treatment receiving group.

\section{Discussion}

In the present study, maximum number of patients was in the 40-49 years age group (30.4\%). The mean age was $45.9 \pm 11.75$ years. British Association of Physical Medicine showed most patients fell in the 40 to 60 years age group, which is also favorable to this study. ${ }^{15}$ Irvine et al found almost equal number (223 females and 230 males) of matched male and female patients and found slight preponderance of male over females. ${ }^{16}$ This is much nearer to our study. Maximum patients were housewife $49(39.2 \%)$ and the table workers were in the second position (20.8\%) in this study. Bhattacharjee $\mathrm{B} \mathrm{N}$ et al found that highest number of patients was table worker and housewife was second. ${ }^{17}$ This may be due to more awareness development amongst female persons about their health. In the present series, significant improvement was observed in response to manual home cervical traction. The result is in favour of the results presented by the British Association of Physical Medicine. ${ }^{15}$ They also found improvement with cervical traction (92.0\%). Swezey RL et al found significant improvement with home cervical traction. ${ }^{18}$ They used simple, in-expensive over-the-door home cervical traction method of treatment requiring 5 minutes of cervical traction twice daily. They found $81.0 \%$ relief of symptoms in cervical spondylosis which supports the findings of our study because we used home cervical traction daily for 15 minutes.

Graham NR supports intermittent traction over continuous traction. ${ }^{19}$ Sarfaraj $\mathrm{M}$ et al found effectiveness of cervical traction in cervical radiculopathy. ${ }^{20}$ This supports the results of our study also. Caldwell et al treated 577 patients of cervical syndrome and found $82 \%$ good results with constant traction. ${ }^{21}$ This is also favourable to the present study because constant traction was used here. The only effects which traction can be expected to achieve due to distraction between vertebrae at the intervertebral disc and apophyseal joints, tensing the longitudinal ligaments of the spinal column, and slight widening of the intervertebral foramina. ${ }^{22}$ Shakoor MA et al found that there was significant improvement in response to traction group, where motorized cervical traction was given along with exercise and NSAIDs. ${ }^{23}$ Caldwell JW et al applied neck muscle exercises and found good results. ${ }^{21}$ Many studies stated that strength training and some specific exercise was effective moderately to reduce pain and improving function in neck disorders. ${ }^{24-25}$ Tanaka $\mathrm{S}$ et al found significant relationship of activities of daily living with joint disorders. ${ }^{26}$ Posture correction was applied here and found insignificant improvement. Zaman A K A et al found home cervical traction significantly reduced symptoms of cervical radiculopathy. ${ }^{27}$ But Bagheripour $B$ et al found no significant improvement of the patients with cervical spondylosis by over-the-door home cervical traction. ${ }^{28}$ Actually their sample size was very small and they give 10 session of traction only. Wong LKF et al suggested cervical traction in incline position for better improvement. ${ }^{29}$

In the present series, traction was given in $15^{\circ}$ inclined posture which also a factor for important of our patients. Cervical traction stretches the posterior cervical region and to enlarge the interspaces at the intervertebral foramina. Probably due to this minimal distraction, there were good results in manual continuous home cervical traction which can be applied as necessary basis at home. So, it may reduce the dose of NSAIDs to avoid side effects also.

\section{Conclusion}

Manual continuous home cervical traction may be an effective adjunct to reduce symptoms of cervical spondylosis when it is used with conventional treatment. And using manual home cervical traction, daily dose of analgesics can be reduced also.

Conflict of interest: There was no conflict of interest.

\section{Funding: None}

Ethical approval: IRB of BSMMU

Submitted: $15^{\text {th }}$ July, 2019

Final revision received: $16^{\text {th }}$ March, 2020

Accepted: $19^{\text {th }}$ March, 2020

Published: $1^{\text {st }}$ August, 2020 


\section{References}

1. Bajaj P, Bajaj P, Nielsen $T$ G, Nielsen L A. Osteoarthritis and its association with muscle hyperalgia: an experimental controlled study. Pain 2001; 93:107-14.

DOI: $10.1016 / \mathrm{S} 0304-3959(01) 00300-1$

2. Cluni GPR and Ralston SH. Rheumatology and bone disease. In: Ralston SH, Penman ID, Strachan MWJ, Hobson RP editors. Davidson's Principle and Practice of Medicine. Edinburgh: ELSEVIRER. 2018. $p p$ 981-1162.

3. Barry M, Jenner J R. Pain in the neck, shoulder and arm. B M J 1995; 310:183-86.

4. Cheng JS, Mc Girth MJ, Devin C In: Firestein GS, Budd RC, Gabriel SE, Mcinnes IB, O'Dell JR, editors: Kelley's Text Book of Rheumatology. 9th ed. Philadelphia, Elsevier Saunders 2013: 625-38.

5. Khan k, Yasmeen S, Ishaque F, Imdad F, Lal W, Sheikh SA et al. Effectiveness of manual traction and other physiotherapy treatment in the management of painful cervical radiculopathy. Int J Physiother 2016; 3: 286-90.

6. Qayyum S, Waqas S, Asim HM. Outcomes of Mechanical Traction and Manual Therapy in C5-C6 Cervical Spondylosis for Radicular Pain Relief. P J M H S 2017; 11:1100-1102. https://pdfs.semanticscholar.org/c854/022b77e73f2 57c30674947fa3ad6347a48f5.pdf

7. Mohindra Y; Clinical and occupational aspect of cervical spondylosis, J Indian Med. Assoc. 1981;77:8-9

PMID: 7328326

8. Alam M N, Haq S A, Moyeenuzzaman M, Samad $\mathrm{M}$ A, Choudhury MKQ, Das $\mathrm{K} K$ et al. Rheumatological Disorders in I P G $M$ \& $R$. Bangladesh J Medicine 1996; 7:1-7.

9. Berman M B, Bausell R B. The use of nonpharmacological therapies by pain specialists. Pain 2000; 85:313-15.

DOI: $10.1016 / \mathrm{S} 0304-3959(00) 00258-\mathrm{X}$

10. Dieppe P, Szebenyl B, Evidence Based Rheumatology. The J Rheamatol. 2000: 4-6

11. Haines_T, Gross_A, Burnie_SJ, Goldsmith_CH, Perry_L. Patient education for neck pain with or without radiculopathy. Cochrane Database of Systematic Reviews. 2009, Issue 1. Art. No.: CD005106.

DOI: 10.1002/14651858.CD005106.pub3.

12. Shakoor MA, Ahmed MS, Kibria G, Khan AA, Mian MAH, Hasan SA et al. Effect of Cervical Traction \& Exercise therapy on in Cervical Spondylosis. Bangladesh Med Res Counc Bull. 2002; 28: 61-69.

PMID: 12825763
13. Saiyed AA, Saiyad $M$, Talati N, Sheth $M$. Immediate Effect of Intermittent Cervical Traction in Supine versus Sitting Position on Heart Rate and Blood Pressure in Healthy Young Individuals. JMSCR 2014; 2: 1149-56.

http://jmscr.igmpublication.org/v2i5/37\%20jmscr.pdf

14. Rueda VG, López de Celis C, Barra López M E, Uribarren AC, Tomás SC, García $\mathrm{CH}$. Effectiveness of a specific manual approach to the suboccipital region in patients with chronic mechanical neck pain and rotation deficit in the upper cervical spine: study protocol for a randomized controlled trial. BMC Musculoskeletal Disorders. 2017; 18:384.

DOI 10.1186/s12891-017-1744-5.

15. British Association of Physical Medicine. Pain in the neck and arm; A multicentre trial of the effect of physiotherapy. Br Med J. 1966;1: 253-58.

DOI: $10.1136 /$ bmj.1.5482.253

16. Irvine DH, Foster JB, Newell DJ, Klukvin BN. Prevalence of cervical spondylosis in general practice. Lancet 1965;1:1089-92.

17. Bhattacharjee $B \mathrm{~N}$, Islam $\mathrm{M}$ Q. Epidemiological aspects of cervical spondylosis and evaluation of conservative treatment. Bangladesh Medical Journal 2000; 29:21-24.

18. Swezey R L, Swezey A M, Warner K. Efficacy of home cervical traction therapy. Am J Rehabil 1999; 78:30-2.

DOI: $10.1097 / 00002060-199901000-00008$

19. Graham NR, Gross A. Mechanical traction for mechanical neck disorders: A systematic review. J Rehabil Med.2006; 38: 145- 52.

DOI: $10.1080 / 16501970600583029$

20. Sarfaraj M, Deepali D. Effectiveness of manual cervical traction and mechanical cervical traction with neural mobilization in cervical radiculopathy. International Journal of Advance Research and Development. 2018; 3:114-19. https://www.ijarnd.com/manuscripts/v3i5/V3I51198.pdf

21. Caldwell JW, Krusen EM. Effectiveness of cervical traction in treatment of neck problems: Evaluation of various Methods. Archiv Phys Med Rehabail. 1962; 5:214-21.

22. Nichols $P$ T R. Rehabilitation Medicine- The Management of Physical Disabilities. $2^{\text {nd }}$ ed. Butterworth \& co Ltd, London-Boston 1980: 11-31.

23. Shakoor MA, Islam MQ, Moyeenuzzaman M, Mian M AH, Khan S. Effects of cervical traction and short wave diathermy on the patients with neck pain. Journal of Dhaka Medical College. 2001; 10:91- 95 .

24. Kay_TM, Gross_A, Goldsmith_CH, Hoving_JL, Brønfort_G. Exercises for mechanical neck 
disorders. Cochrane Database of Systematic Reviews. 2005, Issue 3. Art. No.: CD004250.

DOI: $10.1002 / 14651858 . C D 004250 . p u b 3$.

25. Aydin NA, Kamil Yazicioglu K. Cervical Intermittent Traction: Does it Really Work in Cervical Radiculopathy Due to Herniated Disc? Turk J Phys Med Rehab 2012; 58:277-82. DOI: $10.4274 /$ tftr.44712

26. Tanaka S, Hachisaka K, Ogata H, Kobayashi Y, Tanaka H. Effect of activities of daily living on fibre type atrophy of the vastas lateralis muscle in patients with joint disorders. Am J Phys Med Rehabil 1998; 77: 122-27. DOI: 10.1097/00002060-199803000-00008

27. Zaman AKA, Shakoor MA, Moyeenuzzaman M, Mandal MA, Rahman HNM. Evaluation of effect of home cervical traction on patients with cervical spondylotic radiculopathy. KYAMC Journal 2018; 9:65-68.

DOI: $10.3329 /$ kyamcj.v9i2.38150

28. Bagheripour B, Kamyab M, Azadinia F, Amiri A, Akbari M. The efficacy of a home-mechanical traction unit for patients with mild to moderate cervical osteoarthrosis: A pilot study. Med J Islam Repub Iran. 2016; 30:386.

PMID: 27493930

29. Wong L K F, Luo Z W, Kurusu N. The effect of traction position in cervical traction therapy based on dynamic simulation models. J Biomedical Science and Engineering 2017; 10: 243-56. DOI: $10.4236 /$ jbise. 2017.105019 